Atmos. Chem. Phys., 10, 6889-6899, 2010

www.atmos-chem-phys.net/10/6889/2010/

doi:10.5194/acp-10-6889-2010

(C) Author(s) 2010. CC Attribution 3.0 License.

\title{
Atmospheric diurnal variations observed with GPS radio occultation soundings
}

\author{
F. Xie ${ }^{1, *}$, D. L. Wu ${ }^{1}$, C. O. Ao ${ }^{1}$, and A. J. Mannucci ${ }^{1}$ \\ ${ }^{1}$ Jet Propulsion Laboratory, California Institute of Technology, Pasadena, California, USA \\ *now at: Joint Institute for Regional Earth System Science and Engineering (JIFRESSE), University of California, Los \\ Angeles, California, 90095, USA
}

Received: 5 September 2009 - Published in Atmos. Chem. Phys. Discuss.: 26 November 2009

Revised: 29 June 2010 - Accepted: 11 July 2010 - Published: 26 July 2010

\begin{abstract}
The diurnal variation, driven by solar forcing, is a fundamental mode in the Earth's weather and climate system. Radio occultation (RO) measurements from the six COSMIC satellites (Constellation Observing System for Meteorology, Ionosphere and Climate) provide nearly uniform global coverage with high vertical resolution, all-weather and diurnal sampling capability. This paper analyzes the diurnal variations of temperature and refractivity from three-year (2007-2009) COSMIC RO measurements in the troposphere and stratosphere between $30^{\circ} \mathrm{S}$ and $30^{\circ} \mathrm{N}$. The RO observations reveal both propagating and trapped vertical structures of diurnal variations, including transition regions near the tropopause where data with high vertical resolution are critical. In the tropics the diurnal amplitude in refractivity shows the minimum around $14 \mathrm{~km}$ and increases to a local maximum around $32 \mathrm{~km}$ in the stratosphere. The upward propagating component of the migrating diurnal tides in the tropics is clearly captured by the GPS RO measurements, which show a downward progression in phase from stratopause to the upper troposphere with a vertical wavelength of about $25 \mathrm{~km}$. At $\sim 32 \mathrm{~km}$ the seasonal variation of the tidal amplitude maximizes at the opposite side of the equator relative to the solar forcing. The vertical structure of tidal amplitude shows strong seasonal variations and becomes asymmetric along the equator and tilted toward the summer hemisphere in the solstice months. Such asymmetry becomes less prominent in equinox months.
\end{abstract}

Correspondence to: F. Xie

(feiqin.xie@jpl.nasa.gov)

\section{Introduction}

Driven by the daily persistent solar heating, the diurnal cycle is one of the fundamental variations in the Earth's weather and climate system, which modulates dynamical, hydrological, radiative, and chemical processes throughout the atmosphere. Observations of the diurnal variation can be found in many atmospheric variables. Near the ground, weather reports show that surface air temperature, pressure, winds, precipitation (Dai and Deser, 1999; Dai et al., 1999) and precipitable water vapor (Dai et al., 2002) vary greatly in $24 \mathrm{~h}$. In the troposphere, satellite radiance measurements reveal a significant diurnal cycle of hydrological processes in terms of precipitation (Nesbitt and Zipser, 2003), deep convection, cloudiness and upper tropospheric humidity (UTH) (e.g., Tian et al., 2004, 2005; Chung et al., 2007). From the upper troposphere to the mesosphere and thermosphere, the propagating tidal waves from the water vapor and ozone heating have been extensively investigated and described in the monograph by Chapman and Lindzen (1970). The latest observations of the tidal waves can be found in radiosonde sounding (Tsuda et al., 1994, Huang et al., 2009), lidar (e.g., Williams et al., 1998; States and Gardner, 2000 and She et al., 2002), radar (e.g., Tsuda et al., 1988), and satellite observations (e.g., Hays et al., 1994; McLandress et al. 1996; Wu et al., 1998; Zeng et al., 2008).

The atmospheric diurnal cycle is a process that must be represented realistically in global and regional models for numerical weather and climate prediction. However a thorough understanding of physical mechanisms and processes from the planetary boundary layer (PBL) as well as in the

Published by Copernicus Publications on behalf of the European Geosciences Union. 
troposphere in these models is lacking (e.g., Slingo et al., 1987; Randall et al., 1991; Lin et al., 2000; Yang and Slingo, 2001; Betts and Jakob, 2002; Dai and Trenberth, 2004; Tian et al., 2004). Poor representation of the diurnal cycle in climate models could lead to systematic biases in the mean climate (Keckhut et al., 2001; Neale and Slingo, 2003). In addition, sampling the diurnal cycle is also critical for detecting and monitoring subtle trends in climate change (Dai, 1999).

Characterizing and understanding the atmospheric diurnal cycle requires measurements with sufficient spatial and temporal resolutions for both regional and global studies. Conventional satellite observations (e.g., passive infrared and microwave sounder) provide high spatial and temporal resolution atmospheric measurements but with relatively poor vertical resolution and accuracy. Despite the existence of high vertical resolution temperature measurements in the troposphere and lower stratosphere from radiosondes, and temperature and wind measurements in the mesosphere and lower thermosphere from lidars and radars, these measurements are of limited use for global analyses because of their limited geographical and temporal coverage.

Atmospheric profiling with the GPS Radio Occultation (RO) has emerged as a relatively new technique to provide high-precision temperature and water vapor measurements with global coverage and high vertical resolution $(\sim 200 \mathrm{~m}$ in the troposphere to $\sim 1.4 \mathrm{~km}$ in the stratosphere) (Kursinski et al., 1997). Insensitive to clouds and precipitation, GPS RO measurements are especially valuable for studying the diurnal variation in the troposphere (Kursinski et al., 1997). Zeng et al. (2008) studied the diurnal temperature variation in the tropics using GPS/CHAMP (CHAllenging Minisatellite Payload) observations during 2001-2005. Pirscher et al. (2007) and Zeng et al. (2008) specify that the orbit configuration of CHAMP allows a complete 24:00 h local time coverage within 130 days. Zeng et al. (2008) further explain that due to the limb sounding measurement principle, the effective repeat period is obtained every 108 days at the equator. Due to a slow variation in the equatorial diurnal tide, Zeng et al. (2008) assumed that the diurnal tide was invariant during the CHAMP diurnal sampling period and was able to extract vertical, seasonal, and latitudinal structures of the migrating component of the tide from a composite of 51-month CHAMP temperature profiles at altitudes of 10-30 km. However, their diurnal analysis was limited to the temperature data, not including the lower troposphere and upper stratosphere.

Since its launch in April 2006, the six-satellite constellation COSMIC (Constellation Observing System for Meteorology Ionosphere and Climate) RO mission yields rather dense sampling (over 2000 profiles per day) around the globe (Anthes et al., 2008). More importantly, the open-loop tracking receivers on all COSMIC satellites have significantly improved the RO sounding capability by acquiring a large number of measurements at the PBL altitudes (Sokolovskiy et al., 2006; Ao et al., 2009). In the past, high water va- por variability prevented the close-loop receiver (such as one equipped on CHAMP and many others) from properly tracking the GPS transmitter signals, resulting in retrieval failure and large bias in the lower troposphere (Ao et al., 2003; Beyerle et al., 2003). Like the CHAMP orbit, the COSMIC satellite orbits precess with time. However, with the six satellites, the full diurnal cycle can be sampled well within one month on a global basis. By December 2006, the six satellites were spread out far enough in local time to yield a nearly complete diurnal sampling, and the orbit configuration in 2007 has further improved for the diurnal studies. Each single COSMIC satellite (in final orbit) has a drifting rate of about $-2^{\circ} /$ day, relative to the Earth's mean motion of about $+1^{\circ}$ day. Thus, the six satellites, with a $30^{\circ}$ orbital plane spacing, give a full diurnal cycle sampling within 10 days at low and midlatitudes and within about one month for higher latitudes (Pirscher et al., 2007). However, the local time sampling at high latitudes becomes irregular within one month, because the ascending and descending branch of the orbit move closer together in terms of local time sampling (Pirscher et al., 2009) Pirscher et al. (2010) further demonstrates that the current COSMIC local time sampling is insufficient within one month for diurnal analysis beyond $50^{\circ}$ latitude of both hemisphere. In particular the high atmospheric variability (e.g., planetary waves at high latitudes during winter season) could result in large aliasing errors into the diurnal signals due to the insufficient COSMIC sampling.

In this study, we analyze three-year (2007-2009) COSMIC RO soundings over low latitudes $\left(30^{\circ} \mathrm{S}\right.$ to $\left.30^{\circ} \mathrm{N}\right)$ to derive vertical structures of the diurnal variation of temperature and refractivity at altitudes from the lower troposphere to the upper stratosphere. Section 2 describes the COSMIC dataset and the harmonic analysis method to extract the diurnal signals. In Sect. 3, the amplitude and phase of the diurnal variations (e.g., the migrating tide) close to equator $\left(10^{\circ} \mathrm{S}\right.$ to $10^{\circ} \mathrm{N}$ ) are analyzed and compared to other observations and the well-established tidal wave theory. We further present time series and zonal-mean structures of the diurnal amplitude of the RO refractivity from the middle troposphere to the upper stratosphere in Sects. 4-5. Discussions, conclusions and future work can be found in Sects. 6-7.

\section{Data sampling and analysis}

\subsection{GPS Radio Occultation (RO) sounding technique}

GPS RO technique senses the atmosphere by receiving the GPS radio signals at two L-band frequencies (L1 1.6 GHz and $\mathrm{L} 2 \sim 1.2 \mathrm{GHz}$ ) from a moving LEO (Low Earth Orbit) satellite receiver. As the LEO receiver sets or rises behind the horizon relative to the transmitting GPS satellite, the radio wave is refracted (or bent) and its travel time is delayed due to variations of refractivity. The basic measurements in GPS RO are the time series of GPS carrier phase and signal 
amplitude recorded at the LEO receiver. From the precise determination of the GPS orbits and the location of the receiver, the excess phase, defined as the difference between the measured phase and that predicted for a vacuum, is also accurately calculated and corrected for GPS and receiver clock errors. The excess phase and amplitude are then used to derive the bending angle as a function of tangent height, from which the refractivity profile can be retrieved from the top of the atmosphere to the lower atmosphere with the so-called onion-peeling approach. The temperature and humidity profiles can then be further derived from the refractivity (Kursinski et al., 1997; Rocken et al., 1997). Extensive validation and evaluation of the precision and accuracy of the RO measurements against other observations and models have been carried out by many authors (e.g., Kuo et al., 2004; Schreiner et al., 2007).

In the neutral atmosphere, the refractivity, $N$, a dimensionless quantity defined as $N=(n-1) \times 10^{6}$, where $n$ is the refractive index, is related to the atmospheric pressure $(P$ in $\mathrm{hPa}$ ), temperature ( $T$ in Kelvin), and water vapor partial pressure $\left(P_{\mathrm{w}}\right.$ in hPa) through (Smith and Weintraub 1953)

$N=b_{1} \frac{P}{T}+b_{2} \frac{P_{\mathrm{w}}}{T^{2}}$,

where $b_{1}=77.6 \mathrm{~K} \mathrm{hPa}^{-1}$ and $b_{2}=3.73 \times 10^{5} \mathrm{~K}^{2} \mathrm{hPa}^{-1}$. The refractivity profile can be retrieved from the bending angle profile from near the surface up to $\sim 60 \mathrm{~km}$ before the measurements become too noisy. The moisture contribution to the refractivity can be neglected at altitudes above $\sim 8 \mathrm{~km}$ (in the tropics) where the water vapor volume mixing ratio is usually less than $10^{-4}$ (Kursinski et al., 1997). In this case, Eq. (1) is reduced to:

$N=b_{1} \frac{P}{T}=\left(b_{1} \cdot R\right) \cdot \rho=k \cdot \rho$,

where the gas constant $R=287 \mathrm{~J} \mathrm{~kg}^{-1} \mathrm{~K}^{-1}, \quad k=b_{1}$. $R=222.71 \mathrm{~J} \mathrm{~kg}^{-1} \mathrm{~Pa}^{-1}$, and $\rho$ is density of the atmosphere that is proportional to the refractivity. Consequently pressure can be obtained from density (or refractivity) by integrating the hydrostatic equilibrium equation. The integration starts from a pressure level high in the atmosphere with an a priori temperature guess. The initial pressure error due to the temperature guess decreases rapidly as integration moves deeper into the atmosphere (Kursinski et al., 1997). The temperature can then be inferred via Eq. (2) with the dry atmosphere assumption, which can be generally hold throughout the stratosphere and the cold, dry upper troposphere for temperature less than $250 \mathrm{~K}$. The retrieval is switched to moisture retrieval where temperature is greater than $250 \mathrm{~K}$. In the moisture retrieval, the pressure and water vapor pressure can be derived given an a priori temperature profile, which is usually obtained from global analysis data (Hajj et al., 2002). Alternatively, humidity and temperature can be retrieved simultaneously using 1-D variational analysis provided the background information from model analysis (Healy and Eyre, 2000; Kursinski et al., 2000; Poli et al., 2002).

In the moist troposphere, the refractivity is a weighted sum of dry air density and water vapor density, and thus is affected by both temperature and water vapor pressure. As shown in Fig. $6 f$ of Xie et al. (2008) based on a mid-latitude radiosonde profile, a $1 \mathrm{~K}$ perturbation of temperature corresponds to a $\sim 0.4 \%$ refractivity change at all altitudes. On the other hand, the derivative of refractivity with respective to specific humidity depends on the amount of water vapor, which is a strong function of height. Roughly speaking, a $1 \mathrm{~g} / \mathrm{kg}$ change in specific humidity $q$ corresponds to a $\sim 2.5 \%$ change in refractivity but can vary slightly with temperature. For example, inside a well-mixed PBL where specific humidity is about $q=8 \mathrm{~g} / \mathrm{kg}$, the ratio is $\sim 2.2 \% /(\mathrm{g} / \mathrm{kg})$; at the top of the PBL, around $1.8 \mathrm{~km}$, where $q=3 \mathrm{~g} / \mathrm{kg}$, the ratio is $2.7 \% /(\mathrm{g} / \mathrm{kg})$; in the middle troposphere $(\sim 5 \mathrm{~km})$, where $q=0.8 \mathrm{~g} / \mathrm{kg}$, the ratio is $\sim 3 \% /(\mathrm{g} / \mathrm{kg})$.

\subsection{COSMIC RO data and sampling}

In this study, we use COSMIC RO level-2 refractivity and temperature data in 2007-2009 as retrieved at NASA Jet Propulsion Laboratory (JPL) (Hajj et al., 2002; Ao et al., 2009). The retrieved profiles are reported as a function of geometric height above mean-sea-level (MSL). COSMIC acquires about 2000 occultations a day, however, the number of valid RO profiles is reduced after the calibration and quality control procedure. For comparison purpose, the RO retrievals of the same period provided by UCAR (University Corporation for Atmospheric Research) is also analyzed. The dataset difference between the two data center is well described in Ho et al. (2009). The current JPL retrievals used in this paper apply double differencing calibration during 2007 and 2008, which has resulted in a large number of calibration failures due to the lack of required ground reference station data (especially during the early period of 2008). Single differencing (Wickert et al., 2002) is applied for year-2009 in JPL retrievals and for all UCAR retrievals. Meanwhile, a relatively stringent quality-control procedure applied at JPL data center (e.g., RO profiles with temperatures differing by more than $10 \mathrm{~K}$ from ECMWF analysis or with refractivity differing by more than $10 \%$ from ECMWF at any altitude below $40 \mathrm{~km}$ are abandoned) further reduces the sampling (especially over polar region, where large temperature variation due to planetary waves and gravity waves might not be resolved by the model) by about $25 \%$ (Ho et al., 2009). The total number of soundings at each year for both data centers is shown in Table 1. Note that the JPL data center provides less sounding than UCAR, there are $\sim 25 \%$ less RO profiles in $2007, \sim 40 \%$ less in 2008 and $\sim 37 \%$ less in 2009 . The difference in profile number is caused by the implementation of different calibration technique as well as different quality control procedures. 
Table 1. COSMIC RO Soundings from JPL and UCAR Data Centers.

\begin{tabular}{lrrr}
\hline COSMIC-RO & Year 2007 & Year 2008 & Year 2009 \\
\hline JPL Retrievals & 453031 & 366070 & 394630 \\
UCAR Retrievals & 609912 & 638309 & 628808 \\
\hline
\end{tabular}

The JPL temperature retrievals are scientifically useful at heights ranging from $\sim 8 \mathrm{~km}$ (in the tropics) to $\sim 40 \mathrm{~km}$. The upper boundary is limited by the measurement noise (Kursinski et al., 1997) whereas the lower boundary is limited by the ambiguity of temperature and water vapor that is inseparable in the upper troposphere. On the other hand, the refractivity measurement is useful over a much greater height range $(0-50 \mathrm{~km})$ but requires careful interpretation to connect it to atmospheric physical quantities. Therefore, in the following sections, besides the RO temperature, refractivity profiles are also used to demonstrate the vertical structure of atmospheric diurnal variation for a wider vertical range of the neutral atmosphere. Note that UCAR RO retrievals have both the temperature and refractivity up to $60 \mathrm{~km}$.

In this paper, the refractivity at pressure levels over $800 \mathrm{hPa}$ (below $2 \mathrm{~km}$ ) are not studied because a frequent negative bias has been observed in the refractivity retrievals, likely contaminated by the presence of super-refraction (or ducting) condition near the atmospheric boundary layer top (Sokolovskiy, 2003; Xie et al., 2006; Ao, 2007; Xie et al., 2010). The biased RO retrievals are usually found in the tropical and subtropical regions and need to be dealt with carefully (Xie et al., 2006) before being used for scientific analysis.

In the following sections, if not otherwise noted, the diurnal variation results are based on JPL retrievals.

\subsection{Linear harmonic analysis method}

The JPL temperature and refractivity retrievals are output at $\sim 50 \mathrm{~m}$ and $\sim 400 \mathrm{~m}$ interval vertically at altitudes below and above $20 \mathrm{~km}$, respectively. In this study, we interpolate (using cubic splines) each profile onto 50 standard vertical pressure levels (e.g., 1000, 950, .. 4, 3, 2.2, 1.7, 1.3, $1 \mathrm{hPa}$ ), and then bin the data into twelve local solar time (LST) bins with two-hour width in every $5^{\circ}$ latitude band. Generally the COSMIC satellite configuration results in denser RO soundings in the mid-latitude and high latitude compared with tropics. For example, in the year 2007, the monthly average numbers of COSMIC soundings at a 2-h bin is 54 in a $5^{\circ} \mathrm{N}$-latitude band (centered at $2.5^{\circ} \mathrm{N}$ ), 87 at $25^{\circ} \mathrm{N}, 125$ at $50^{\circ} \mathrm{N}$ and 37 at $75^{\circ} \mathrm{N}$. Roughly $75 \% \mathrm{RO}$ soundings reach at $800 \mathrm{hPa}(\sim 2 \mathrm{~km})$ and about $40 \%$ reach $950 \mathrm{hPa}(\sim 0.5 \mathrm{~km})$ above MSL. However, due to topography over continental area, the exact percentage of RO soundings reaching the low- est $2 \mathrm{~km}$ above the Earth surface is actually higher. The zonal mean temperature $T$ and refractivity $N$ at the twelve local time bins are derived on a monthly basis. After the monthly mean is removed, a harmonic analysis with 24-h and 12$\mathrm{h}$ components is applied to compute the diurnal and semidiurnal amplitudes and their phases for each latitude and height bin (Chapman and Lindzen, 1970; Wu et al., 1995; Dai et al., 2002). A brief summary of the harmonic analysis method is given below.

Given a time series $y_{i}, i=1,2, \ldots, M,(M$ is the maximum number of samples for a day, in this study, $M=12$ ) as a function of local solar time $t_{i}$, it can be decomposed into three components:

$y_{i}\left(t_{i}\right)=\bar{y}+\sum_{n} S_{n}\left(t_{i}\right)+\varsigma$

where, $\bar{y}$ is the daily mean; $S_{n}$ is the harmonics with different periods and $\zeta$ is the residual noise. The harmonics with different time scales can be expressed as:

$S_{n}\left(t_{i}\right)=A_{n} \cos \left(n t^{\prime}-\phi\right)=a_{n} \cos \left(n t^{\prime}\right)+b_{n} \sin \left(n t^{\prime}\right)$

where, $t^{\prime}$ is LST expressed in degree or radians (i.e., $t^{\prime}=$ $2 \pi t_{i} / 24$, where $t_{i}$ is LST in hours), $n=1,2,3,4, \ldots$ denotes harmonics with periods of $24,12,8,6, \ldots$ hours, respectively; $A_{n}$ is the amplitude (note that the peak-to-peak amplitude is $2 A_{n}$ ); $\phi$ is the phase (time of the maximum $y_{i}$ in LST). Here, we only focus on the most dominant mode, i.e., the diurnal $\left(S_{1}\right)$ component.

Note that the observed time series could contain higherorder harmonics of the diurnal variations (such as period $\leq 12 \mathrm{~h}$ ) and residuals $(\varsigma)$ due to measurement and sampling errors. The COSMIC sampling rate of local times might not be enough to catch the semi-diurnal and finer time scale $(<12 \mathrm{~h})$ variations. On the other hand, the zonal average helps remove most of the longitudinal variability likely due to the planetary waves and nonmigrating tides (Wu et al., 1998) but the spectral aliasing from other wave components may induce additional errors to the diurnal component of interest. The signal-to-noise ratio (SNR) of the derived amplitudes is thus calculated as the ratio of the fitted amplitude over the residual error after the diurnal and semi-diurnal fitting (i.e., $A_{n} / \varsigma$ ).

\section{Tropical diurnal variations - the tidal waves}

The diurnal variation in the tropical region, investigated for decades, is one of the most well-observed and understood phenomena among tropical variabilities. The propagating (migrating with the Sun) component of the atmospheric diurnal variations is also called the migrating tide. It has a weak variation in terms of magnitude, and can be used as good validation of the RO sensitivity and the retrieval quality. In this section, we derive and characterize the vertical distribution of this tidal wave with the COSMIC RO measurements, and validate the results against some of the earlier studies. 
To derive the vertical distribution of the propagating diurnal component, the tropical $\left(10^{\circ} \mathrm{S}-10^{\circ} \mathrm{N}\right) \mathrm{COSMIC}$ temperature and refractivity soundings in 2007 are used. Figure 1 shows the vertical structure of diurnal amplitudes and phases (i.e., the LST of the maximum amplitude) for temperature (in Kelvin) and refractivity (in percentage) extracted from the monthly averaged data. Note that the total number of RO samples (JPL) in 2008 and 2009 are less than in 2007, however, very similar vertical structures of diurnal variations are derived for both years (not shown).

The propagating tidal wave, which migrates with the sun, dominates the tropical diurnal variation in the stratosphere and higher altitudes (e.g. McLandress, 1997). Its propagation nature is evident in the temperature and refractivity data, showing a downward progressing phase profile (Fig. 1b, d) with growing amplitude above $14 \mathrm{~km}$. The vertical wavelength of the diurnal tidal wave is about $25 \mathrm{~km}$, which is observed in both the temperature and refractivity phase profiles. The migrating tidal wave observed by COSMIC is consistent with one obtained by Zeng et al. (2008) from the multiyear CHAMP data, and with those from the classical tidal theory and model results (e.g., Chapman and Lindzen, 1970; McLandress, 1997). In the stratosphere the maximum refractivity amplitude reaches $\sim 1 \%$, or $\sim 2.5 \mathrm{~K}$ in temperature.

The refractivity and temperature fluctuations are independent but related through Eq. (2) and through the hydrostatic balance equation embedded in the retrieval. Above $\sim 8 \mathrm{~km}$, refractivity is dominated by dry air variability, reflecting mostly geopotential height changes since the temperature retrieval is carried out on pressure surfaces. The temperature and geopotential height tides are expected to be out of phase (e.g., $12 \mathrm{~h}$ difference) at constant pressure levels for the propagating diurnal tide. In addition, the amplitudes of refractivity and temperature variation should be consistent in percentage, as seen in Fig. 1a, c, showing local minima at $\sim 15 \mathrm{~km}$ and $22 \mathrm{~km}$ and a growing trend above $15 \mathrm{~km}$. The minimum diurnal amplitude of temperature $(\sim 0.1 \mathrm{~K})$ and refractivity $(\sim 0.05 \%)$ is found at $15 \mathrm{~km}$. A local maximum diurnal amplitude in both temperature $(0.9 \mathrm{~K})$ and refractivity $(\sim 0.4 \%)$ is found at around $32 \mathrm{~km}$.

Above $40 \mathrm{~km}$, although the temperature retrieval is not available, the refractivity data can still be used to derive atmospheric diurnal variations. Phase and amplitude structure shown in Fig. 1c, d are consistent with the expected upward propagating diurnal tidal mode despite the noisier phase structures and larger monthly variations in amplitude. Above $14 \mathrm{~km}$, the winter and autumn seasons (green and black in Fig. 1a, c) show a larger diurnal amplitude compared to the summer and spring seasons. Between $8 \mathrm{~km}$ and $10 \mathrm{~km}$, the spring season shows the largest diurnal amplitude in temperature and refractivity. Below $5 \mathrm{~km}$, again, the spring season exhibits the largest diurnal amplitude. As the diurnal tide propagates up to the upper stratosphere, the propagating wave component excited from tropospheric water vapor will interfere with the wave component excited by the heating from the ozone layer, which can lead to large variability in the migrating diurnal tide (Chapman and Lindzen, 1970). Note that the tidal wave amplitude tends to increase at higher altitudes due to the exponential decay of the air density (Chapman and Lindzen, 1970; McLandress, 1997). However, ozone heating becomes significant above $12 \mathrm{hPa}(30 \mathrm{~km})$ and reaches maximum around $1 \mathrm{hPa}(47 \mathrm{~km})$ (McLandress, 1997). The temperature variation due to ozone heating tends to reach a maximum at local noon when ozone solar absorption maximizes. However, the propagating temperature tide is out of phase from the ozone heating, which may explain the change of the slope of the phase around $30 \mathrm{~km}$ and lead to non-monotonic structure of tidal amplitude at higher altitudes.

The diurnal variation below $17 \mathrm{~km}$ is complicated by the coexistence of wave forcings and propagation in the region. Figure $1 \mathrm{~b}$ shows that at $10-14 \mathrm{~km}$ the phase of the diurnal temperature variation remains rather constant (at $\sim$ 18:00 LST), but shifts sharply at a few kilometers above that. Similar behavior can be observed from the refractivity (Fig. 1d) but with the phase at $10-14 \mathrm{~km}$ relatively constant at $\sim 06: 00$ LST. It is reflected in the slope of the diurnal phase, which changes at $\sim 17 \mathrm{~km}$ and remains relatively constant up to $40 \mathrm{~km}$.

Figure 1 also shows the median-average of the diurnal amplitude and phase derived from UCAR retrievals (black dashed line). The phase of both temperature and refractivity matches the JPL results very well at all altitudes except below $\sim 7 \mathrm{~km}(400 \mathrm{hPa})$ where phase becomes noisy. While the UCAR diurnal amplitude of both temperature and refractivity agree well with the JPL result in the upper troposphere and lower stratosphere, they become significantly less by $\sim 25-50 \%$ above $24 \mathrm{~km}$ and by $\sim 50 \%$ below $7 \mathrm{~km}$. In comparison with the diurnal variation derived from the ECMWF T799L91 analysis (not shown), the diurnal amplitude from the JPL retrieval is closer to the ECMWF result. However, sampling can affect the diurnal results as well. The UCAR retrieval has about $25 \%$ more soundings compared to JPL retrievals in 2007. We down-sample the UCAR soundings to those matching JPL retrievals and reapply the same diurnal analysis. The vertical structure of diurnal amplitude remain virtually unchanged, which indicates the larger diurnal amplitude observed from JPL soundings above $24 \mathrm{~km}$ are unlikely to be caused by the lack of sampling, but are likely due to the retrieval difference between the two dataset. More discussion is presented in Sect. 6.

The diurnal phases of refractivity below $\sim 7 \mathrm{~km}(400 \mathrm{hPa})$ are rather noisy for both the JPL and the UCAR retrievals, which is likely due to aliasing from insufficient sampling. The monthly COSMIC RO sampling might not be enough to resolve the diurnal variations in the middle and lower troposphere where red-spectral variabilities increase due to weather phenomena. Therefore, only results above $\sim 7 \mathrm{~km}$ $(400 \mathrm{hPa})$ will be presented in the following sections. 

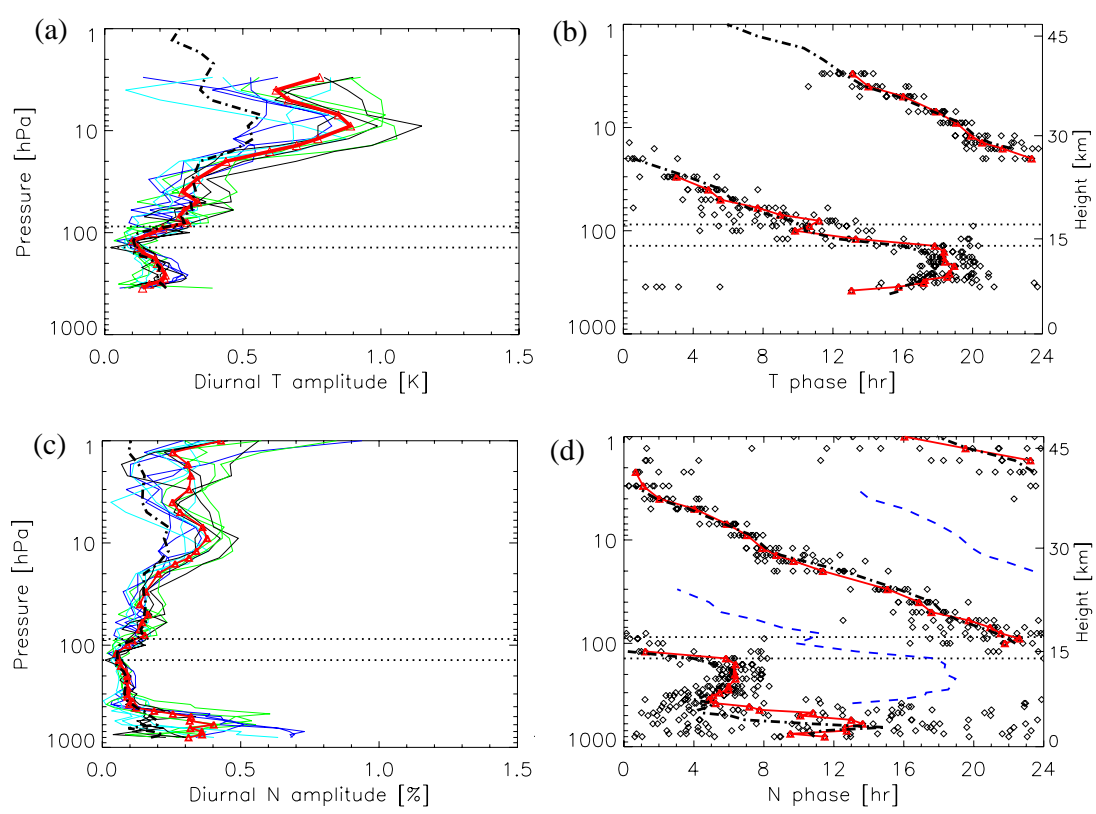

Fig. 1. Vertical structure of the temperature $(\mathbf{a}, \mathbf{b})$ and refractivity $(\mathbf{c}, \mathbf{d})$ amplitude (left panels) and phase (right panels) of diurnal variations over $10^{\circ} \mathrm{S}-10^{\circ} \mathrm{N}$ based on COSMIC RO observations in 2007. Each solid line (a, c) represents one monthly mean amplitude profile whereas phases from the monthly data are shown as open diamond (b, d). The four seasons are denoted by different colors in (a) and (c), e.g., DJF (green), MAM (blue), JJA (cyan), SON (black). The RED thick lines show the annual median values. The blue dashed lines in (d) represents the temperature phase as shown in (b). The black dash-dot lines in all four panels correspond to the annual median-averaged results derived from the UCAR retrievals in 2007. The two black thin dashed lines in each panel mark the altitudes at $14 \mathrm{~km}$ and $17 \mathrm{~km}$, respectively.

\section{Seasonal variations}

Seasonal variations of the migrating component of the diurnal tide can be clearly seen in the middle stratosphere. As shown in Fig. 2 for the three year (2007-2009) time series at $9 \mathrm{hPa}(\sim 32 \mathrm{~km})$, the maximum amplitude of the propagating diurnal temperature tide swings around the equator, depending on time of the year. During the northernhemispheric $(\mathrm{NH})$ winter and spring (October to March), the maximum diurnal temperature amplitude $(\sim 1.2 \mathrm{~K})$ occurs at around $5^{\circ} \mathrm{N}$ in January, whereas the maximum shifts to $5^{\circ} \mathrm{S}$ and weakens during the summer and autumn (June to September), which is opposite to where the solar forcing peaks. A similar seasonal variation was observed with UARS Microwave Limb Sounder data (Wu et al., 1998), CHAMP RO and in the 3-D Canadian Middle Atmosphere Model (CMAM) simulations (Zeng et al., 2008), but not in the simulations with Global-Scale Wave Model Version 2 (GSWM02) (Hagan and Forbes, 2002). The asymmetric structure of the propagating diurnal tide is more pronounced in the mesosphere and lower thermosphere, and more in the solstice months than in the equinox months (McLandress, 1997, 2002).

To characterize the seasonal variation of the diurnal amplitude over a broader altitude range, we analyze the refractivity data at six pressure levels from $\sim 260 \mathrm{hPa}(\sim 10 \mathrm{~km})$ to $\sim 3 \mathrm{hPa}(\sim 40 \mathrm{~km})$ and the results are shown in Fig. 3. Al- though the seasonal variation is similar over the three years, interannual differences are evident in the monthly COSMIC data at some pressure levels. For example, the maximum diurnal amplitude at $\sim 40 \mathrm{~km}$ (centered at the equator) has larger amplitude $(\sim 0.5 \%)$ in February 2008 compared to the other two years. Similarly, at $\sim 18 \mathrm{~km}$, the maximum diurnal amplitude (centered at $5^{\circ} \mathrm{S}$ ) is slightly larger in January 2008.

At $\sim 10 \mathrm{~km}(260 \mathrm{hPa})$, the diurnal amplitude is generally small $(\sim 0.1 \%)$ over the whole domain, and is mostly associated with vertically trapped components. The largest diurnal amplitude is centered around $5^{\circ} \mathrm{S}$ in December-February for all three years. A similar seasonal pattern is also seen at $\sim 18 \mathrm{~km}(80 \mathrm{hPa})$. At this level, the tidal wave starts to propagate freely and the diurnal amplitude doubles. The maximum diurnal amplitude in January 2008 is about 30\% larger than the other two years. At $\sim 20 \mathrm{~km}$, the tidal amplitudes maximize $(0.2 \%)$ close to $5-10^{\circ} \mathrm{S}$ in the North-Hemispheric (NH) winter season.

At $\sim 26 \mathrm{~km}(20 \mathrm{hPa})$, significant diurnal amplitudes (over $0.2 \%$ ) are no longer restricted to the $\mathrm{NH}$ winter months as seen in the lower altitudes, but are limited to be within $20^{\circ} \mathrm{S}$ and $15^{\circ} \mathrm{N}$. The largest diurnal amplitude, however, is still observed at $5-10^{\circ} \mathrm{S}$ in the $\mathrm{NH}$ winter with slightly larger amplitude $(0.3 \%)$. 


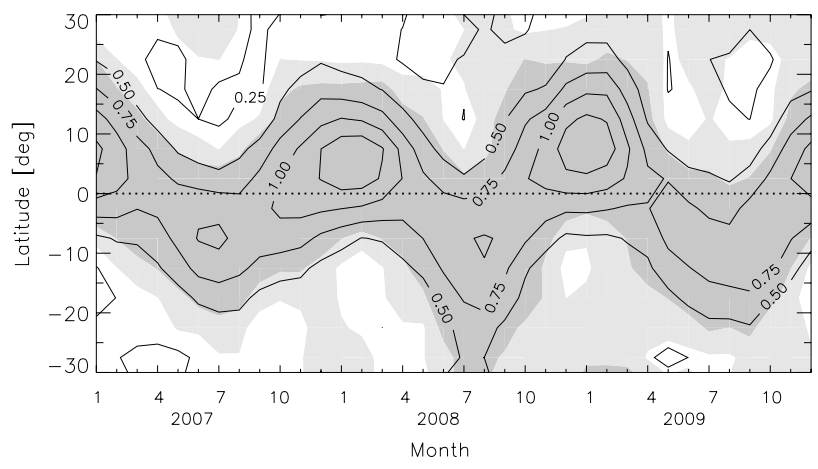

Fig. 2. Amplitudes of the diurnal temperature tide at $9 \mathrm{hPa}$ $(\sim 32 \mathrm{~km})$ as a function of latitude $\left(30^{\circ} \mathrm{S}-30^{\circ} \mathrm{N}\right)$ and month of COSMIC RO observations from 2007 to 2009. The contour interval is $0.25 \mathrm{~K}$. The two-gray-level shaded region denotes the regions where the signal-to-ratio (SNR) of the fitted amplitude over fitting errors are greater than 2 (light gray) and 3 (dark gray), as discussed in Sect. 2.3. Note that almost all amplitudes in the domain have SNR $>1$.

At $32 \mathrm{~km}$, the diurnal amplitude maximum $(0.6 \%)$ drifts around the equator between $5^{\circ} \mathrm{S}$ and $5^{\circ} \mathrm{N}$, anti-correlated with the solar heating change, which peaks at the summertime subtropical latitude. The refractivity variation here is consistent with the diurnal temperature amplitude as seen in Fig. 2. This further illustrates that the refractivity diurnal variation in the stratosphere is dominated by the temperature variations. It is of note that this distinct seasonal pattern is also seen at altitudes between $\sim 28 \mathrm{~km}$ and $\sim 36 \mathrm{~km}$. The maximum diurnal amplitude generally increases at higher altitudes $(\sim 0.3 \%$ at $\sim 28 \mathrm{~km})$ and reaches a maximum $(0.6 \%)$ at $\sim 32 \mathrm{~km}$ but slightly decrease to $\sim 0.5 \%$ at $\sim 36 \mathrm{~km}$ (not shown).

At $\sim 40 \mathrm{~km}$, the maximum diurnal amplitude $(0.5 \%)$ is slightly smaller than those at $\sim 32 \mathrm{~km}$. The seasonal variation of the tropical diurnal tide becomes less asymmetric about the equator, compared to that at $\sim 32 \mathrm{~km}$. Significant diurnal amplitudes $(>0.2 \%)$ are seen in all months and at all latitudes between $30^{\circ} \mathrm{S}$ and $30^{\circ} \mathrm{N}$. The locations of the maximum diurnal amplitudes at January is well collocated with those seen below $\sim 26 \mathrm{~km}$ altitudes.

\section{Monthly climatology}

In this section we analyze the zonal mean vertical structures of diurnal refractivity amplitude for twelve nominal months based on the COSMIC RO from 2007 to 2009 (Fig. 4). Generally speaking, the diurnal amplitudes show relatively small values $(0.1-0.2 \%)$ in the middle and upper troposphere and significantly increase above $\sim 20 \mathrm{hPa}(26 \mathrm{~km})$.

The diurnal amplitudes in the stratosphere exhibit strong seasonal variations. The tropical maximum in the stratosphere, as discussed above, is associated with the propagat-
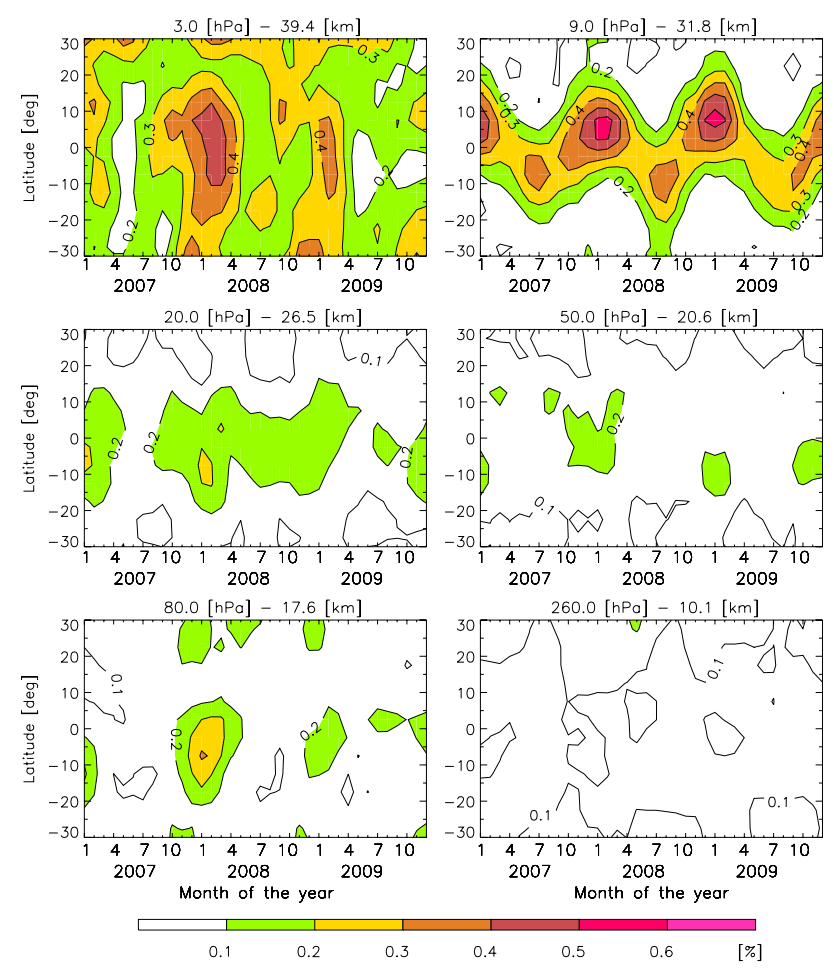

Fig. 3. Three-year time series of diurnal amplitude of refractivity (in percentage) at six pressure levels from $260 \mathrm{hPa}$ to $3 \mathrm{hPa}$.

ing diurnal tide. The vertical structure of the tide is asymmetric along the equator and tilted toward the summer hemisphere in the solstice months. The asymmetry is less prominent in equinox months, especially in April and October. The vertical structure of the zonal mean diurnal amplitude agrees well with CHAMP observations and the CMAM simulations in the upper troposphere and lower stratosphere (e.g., Zeng et al., 2008).

The diurnal amplitude reaches a maximum of $\sim 0.6 \%$ $(\sim 1.5 \mathrm{~K})$ at $\sim 32 \mathrm{~km}$ in January which is twice as large as those seen in July. The stronger tides (over $0.2 \%$ ) extend downward close to the tropopause region $(\sim 17 \mathrm{~km})$ in December-February while only extend down to $\sim 25 \mathrm{~km}$ in other months. Above $\sim 40 \mathrm{~km}(3 \mathrm{hPa})$, large diurnal amplitudes comparable to the maximum tidal amplitude at $\sim 32 \mathrm{~km}$ are seen near $30^{\circ} \mathrm{S}$ in December-January and near $30^{\circ} \mathrm{N}$ in May-October. The large diurnal amplitude above $40 \mathrm{~km}$ extends over larger regions from $-30^{\circ} \mathrm{S}$ to the equator in March and April.

\section{Discussion}

The tropical diurnal tidal wave, although being weak in amplitude, is clearly observed by the high resolution GPS RO technique. Consistent with the CMAM model simulation (e.g., McLandress, 1997), the vertical profiles of the tidal 


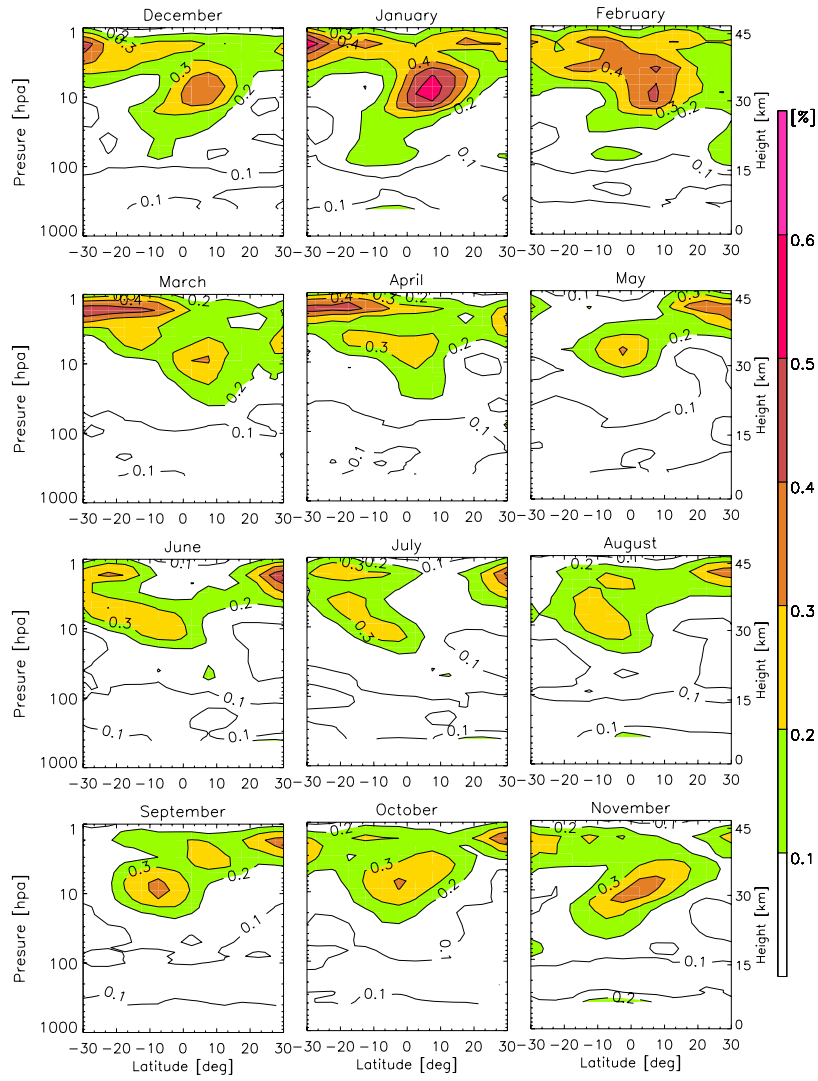

Fig. 4. Three-year averaged (2007-2009) vertical structure of zonal mean diurnal refractivity amplitude (in percentage) in twelve months. Only the pressure leves less than $400 \mathrm{~Pa}$ (or above $\sim 7 \mathrm{~km}$ ) are shown.

amplitude and phase derived from the COSMIC data serve as a validation source for the RO observations. Above the upper troposphere ( $\sim 14 \mathrm{~km}$ in tropics), the diurnal temperature and refractivity variations are out of phase, as expected for the upward propagating tidal wave. The region between 8 and $16 \mathrm{~km}$ is dominated by the water vapor solar heating, which possibly explains the locked phase in the diurnal temperature variation (e.g., 18:00 LST in Fig. 1b). The tropical deep convection from solar heating tends to peak in the late afternoon over land, and a large part of the diurnal variation is driven by the heating over land.

We found in this study that the UCAR retrievals show a smaller diurnal amplitude at altitudes above $\sim 24 \mathrm{~km}$ compared to the JPL retrieval. Further evaluation of the zonal mean variance of UCAR temperature and refractivity retrievals shows almost the same magnitudes as JPL retrievals at altitudes below $30 \mathrm{~km}$ but significantly smaller values above that level. Spectral leakage due to insufficient sampling could cause aliasing from other planetary waves into the diurnal tide. However, when we sample the UCAR soundings to match the JPL sampling we find the vertical structure of the derived diurnal amplitude remains un- changed. This suggests that the larger diurnal amplitude observed from JPL RO soundings is unlikely to be caused by the lack of sampling. We believe that the differences in diurnal amplitudes from the JPL and UCAR data are due to the different approaches used to handle noisy bending angles in the upper stratosphere (Ho et al., 2009). In the JPL retrieval, the bending angles above $50 \mathrm{~km}$ are replaced with exponential extrapolation. Thus the variability of the the bending angle measurements below $50 \mathrm{~km}$ is retained. On the other hand, the UCAR retrieval uses a dynamic optimization method that replaces the bending angle with a weighted average of the data and a climate model fitted to the data by use of two parameters between $20-60 \mathrm{~km}$. The optimization approach helps to stabilize the retrievals in noisy cases by placing more weights on the smooth model; however, it could also suppress the natural variability in the data. These retrieval differences among various data centers need to be carefully addressed.

In the middle and lower troposphere (below $\sim 7 \mathrm{~km}$ ) the phase of the diurnal variation in refractivity shows large month-to-month variability in the tropics (Fig. 1d), not locked to a specific local time. The refractivity in the lower troposphere is strongly influenced by water vapor abundance and the hydrological and dynamical processes near the surface. Studying three-hourly weather data from 15000 worldwide stations, Dai (2001) found that the most frequent (morning) hour of showery precipitation over water is out of phase with those over land and the latter exhibited large seasonal variability. Similar large variability was also reported in wind measurements (Dai and Deser, 1999) and cloud and water vapor data (Soden, 2000; Tian et al., 2004). However, such strong zonal variations of the diurnal amplitude would require very dense RO soundings to suppress aliasing effects. Sampling errors of the current COSMIC soundings would need to be carefully addressed. Moreover, the RO refractivity observations in the lower troposphere (below 2-3 km) are likely to be contaminated by the negative bias in the presence of super-refraction (or ducting) near the atmospheric boundary layer top (Sokolovskiy, 2003; Xie et al., 2006, 2010; Ao, 2007). Such biased RO profiles would need to be corrected (e.g., Xie et al., 2006) before applying for diurnal analysis.

Finally, the RO signals are sensitive to ionospheric structure and perturbations. Ionospheric residuals may affect the diurnal variation observed in the neutral atmospheric parameters (e.g., bending and refractivity), especially in the cases of weak atmospheric signals. Although an ionospheric correction has been made through a linear combination of L1 and L2 bending angle retrievals at a given impact parameter (Vorob'ev and Krasil'nikova, 1994), higher-order residual errors could remain (e.g., Syndergaard, 2000). The ionospheric residual errors (Kursinski et al., 1997) could have diurnal variations related to ionospheric electron density and affect the signal derived in the upper stratosphere.

The observed diurnal variations have an important implication for monitoring the global warming trend in the future. 
Valuable for establishing a consistent, long-term observation, the GPS RO technique is based on the fundamental SI unit in atomic clock calibration and insensitive to orbit geometry and clouds (Schrøder et al., 2003). However, like other climate observing systems, the sampling issue must be adequately addressed to avoid biasing to certain local times or specific geographical locations since climate change signals may be so subtle that any of these biases can be misinterpreted.

\section{Conclusion and future work}

In this paper, we derived the latitudinal and vertical distributions of the diurnal variations in temperature and refractivity over low latitudes by using three-year COSMIC RO soundings. The zonally-averaged diurnal amplitude and phase reveal clear tidal signatures in the tropics, which propagate upwards from around $14 \mathrm{~km}$ to the upper stratosphere (Fig. 1). The annual mean diurnal amplitude tend to be small in the middle and upper troposphere $(0.05-0.2 \%$ in refractivity) with a local minimum of $0.05 \%$ (or $0.1 \mathrm{~K}$ ) at $\sim 14 \mathrm{~km}$; the diurnal amplitude then increases to a maximum of $0.4 \%$ (or $1 \mathrm{~K})$ at $\sim 32 \mathrm{~km}$ in the stratosphere. At this level the maximum 24-h amplitudes of both temperature and refractivity are out phase relative to the maximum solar heating (Fig. 2 and Fig. 3).

The zonal mean diurnal variations exhibit unique vertical structures and seasonal patterns (Fig. 3). The minimum of the 24-h refractivity amplitude is found near the tropopause height and increases at higher altitudes. The vertical structure of the tide is asymmetric across the equator and tilted toward the summer hemisphere in the solstice months. The asymmetry is less prominent in equinox months, especially in April and October.

It would be very interesting to extend the diurnal analysis to the PBL, where differential heating due to land and ocean contrast becomes important. However, the limited sounding samples for the current COSMIC observations and the negative bias in the RO refractivity measurements in the tropical and subtropical regions would need to be carefully considered before applying the diurnal analysis.

The diurnal variations observed by COSMIC RO soundings have important implication for detecting and monitoring climate changes in the future satellite missions. Insufficient diurnal sampling in climate trend monitoring could lead to biases in the detected climate trend. Future RO missions (e.g., the 12-satellite COSMIC-II mission) along with the planned new receiver and antenna technology (Meehan, 2009) are expected to significantly increase RO samples and further improve retrievals by reducing measurement errors and extending the useful range of RO data for global diurnal study at all altitudes and at higher latitudes. Such a dense sounding will enable more accurate determination of the diurnal variation on a global as well as regional basis.
Acknowledgements. This work was performed at the Jet Propulsion Laboratory, California Institute of Technology, under contract with the National Aeronautics and Space Administration (NASA). The authors would like to thank the GPS operational team members: Byron Iijima, Marc Pestanal, Tom Meehan and Larry Young at NASA Jet Propulsion Laboratory for their efforts for making the COSMIC retrievals available. The UCAR retrievals are provided by COSMIC Data Analysis and Archive Center (CDAAC). We also thank Sergey Sokolovskiy, Xiaoqing Pi, Charles McLandress and Jeffrey M. Forbes for very helpful discussions in preparing the paper. We also would like to thank the editor (William Ward) and three anonymous reviewers for helping improve the manuscript.

Edited by: W. Ward

\section{References}

Anthes, R. A., Bernhardt, P. A., Chen, Y., et al.: The COSMIC/FORMOSAT-3 mission early results, B. Am. Meteorol. Soc., 89(3), 313-333, doi:10.1175/BAMS-89-3-313, 2008.

Ao, C. O., Meehan, T. K., Hajj, G. A., Mannucci, A. J., and Beyerle, G.: Lower-troposphere refractivity bias in GPS occultation retrievals, J. Geophys. Res., 108, 4577, doi:10.1029/2002JD003216, 2003.

Ao, C. O.: Effect of ducting on radio occultation measurements: An assessment based on high-resolution radiosonde soundings, Radio Sci., 42, RS2008, doi:10.1029/2006RS003485, 2007.

Ao, C. O., Hajj, G. A., Meehan, T. K., Dong, D., Iijima, B. A., Mannucci, A. J., and Kursinski, E. R.: Rising and setting GPS occultations by use of open-loop tracking, J. Geophys. Res., 114, D04101, doi:10.1029/2008JD010483, 2009.

Betts, A. K. and Jakob, C.: Evaluation of the diurnal cycle of precipitation, surface thermodynamics, and surface fluxes in the ECMWF model using LBA data, J. Geophys. Res., 107(D20), 8045, doi:10.1029/ 2001JD000427, 2002.

Beyerle, G., Gorbunov, M., and Ao, C. O.: Simulation studies of GPS radio occultation measurements, Radio Sci., 38, 1084, doi:10.1029/2002RS002800, 2003.

Chapman, S. and Lindzen, R. S.: Atmospheric Tides Thermal and Gravitational, D. Reidel, Dordrecht, Holland, 200 pp., 1970.

Chung, E. S., Sohn, B. J., Schmetz, J., and Koenig, M.: Diurnal variation of upper tropospheric humidity and its relations to convective activities over tropical Africa, Atmos. Chem. Phys., 7, 2489-2502, doi:10.5194/acp-7-2489-2007, 2007.

Dai, A.: Recent changes in the diurnal cycle of precipitation over the United States, Geophys. Res. Lett., 26(3), 341-344, 1999.

Dai, A. and Deser, C.: Diurnal and variations in global surface wind and divergence fields, J. Geophys. Res., 104(D24), 3110931125, 1999.

Dai, A., Giorgi, F., and Trenberth, K.: Observed and modelsimulated diurnal cycles of precipitation over the contiguous United States, J. Geophys. Res., 104(D6), 6377-6402, 1999.

Dai, A.: Global precipitation and thunderstorm frequencies. Part II: Diurnal variations, J. Clim., 14, 1112-1128, 2001.

Dai, A. and Trenberth, K. E.: The diurnal cycle and its depiction in the Community Climate System Model, J. Clim., 17, 930-951, 2004.

Dai A., Wang, J. H., Ware, R. H., and Hove, T. V.: Diurnal variation in water vapor over North America and its implications for sam- 
pling errors in radiosonde humidity, J. Geophys. Res, 107(D10), 4090, doi:10.1029/2001JD000642, 2002.

Hagan, M. E. and Forbes J. M.: Migrating and nonmigrating diurnal tides in the middle and upper atmosphere excited by tropospheric latent heat release, J. Geophys. Res., 107(D24), 4754, doi:10.1029/2001JD001236, 2002.

Hajj, G. A., Kursinski,E. R., Romans,L. J., Bertiger,W. I., and Leroy, S. S.: A technical description of atmospheric sounding by GPS occultation, J. Atmos. Sol.-Terr. Phys., 64 (4), 451-469, 2002.

Hays, P. B., Wu, D. L., and HRDI Science Team: Observations of the diurnal tide from space, J. Atmos. Sci., 51(20), 3077-3093, 1994.

Healy, S. B. and Eyre, J. R.: Retrieving temperature, water vapour and surface pressure information from refractive index profiles derived by radio occultation: a simulation study, Q. J. Roy. Meteor. Soc., 126(566), 1661-1683, 2000.

Ho, S.-P., Kirchengast, G., Leroy, S., et al.,: Estimating the uncertainty of using GPS radio occultation data for climate monitoring: Intercomparison of CHAMP refractivity climate records from 2002 to 2006 from different data centers, J. Geophys. Res., 114, D23107, doi:10.1029/2009JD011969, 2009.

Keckhut, P., Wild, J. D., Gelman, M., Miller, A. J., and Hauchecorne A.: Investigations on long-term temperature changes in the upper stratosphere using lidar data and NCEP analyses, J. Geophys. Res., 106(D8), 7937-7944, 2001.

Kuo, Y. H., Wee, T. K., Sokolovskiy, S., Rocken, C., Schreiner, W., Hunt, D., and Anthes, R. A.: Inversion and error estimation of GPS radio occultation data, J. Meteorol. Soc. Jpn, 82(1B), 507531, 2004.

Kursinski, E. R., Hajj, G. A., Schofield, J. T., Linfield, R. P., and Hardy, K. R.: Observing Earth's atmosphere with radio occultation measurements using the Global Positioning System. J. Geophys. Res., 102, 23429-23465, 1997.

Kursinski, E. R., Healy, S. B., and Romans, L. J.: Initial results of combining GPS occultations with ECMWF global analyses within a 1DVar framework, Earth Planets Space, 52, 885-892, 2000.

Lin, X., Randall, D. A., and Fowler, L. D.: Diurnal variability of the hydrologic cycle and radiative fluxes: Comparisons between observations and a GCM, J. Clim., 13, 4159-4179, 2000.

McLandress, C., Shepherd, G. G., and Solheim, B. H.: Satellite observations of thermospheric tides: Results from the Wind Imaging Interferometer on UARS, J. Geophys. Res., 101(D2), 40934114, 1996.

McLandress, C.: Seasonal variability of the diurnal tide: Results from the Canadian Middle atmospheric general circulation model, J. Geophys. Res., 102, 29747-29764, 1997.

McLandress, C.: The seasonal variation of the propagating diurnal tide in the mesosphere and lower thermosphere. Part II: The role of tidal heating and zonal mean winds, J. Atmos. Sci., 59(5) 907922, 2002.

Meehan, T.: The TriG digital beam steered sounder, IEEE Aerospace Conference, 1-5, doi:10.1109/AERO.2009.4839464, March 2009.

Neale, R. and Slingo J.: The maritime continent and its role in the global climate: A GCM study, J. Clim., 16, 834-848, 2003.

Nesbitt, S. W. and Zipser E. J.: The diurnal cycle of rainfall and convective intensity according to three years of TRMM measure- ments, J. Clim., 16, 1456-1475, 2003.

Poli, P., Joiner, J., and Kursinski, E. R.: 1DVAR analysis of temperature and humidity using GPS radio occultation refractivity data, J. Geophys. Res., 107(D20), 4448, doi:10.1029/2001JD000935, 2002.

Pirscher, B., Foelsche, U., Lackner, B. C., and Kirchengast, G.: Local time influence in single-satellite radio occultation climatologies from Sun-synchronous and non-Sun-synchronous satellites, J. Geophys. Res., 112, D11119, doi:10.1029/2006JD007934, 2007.

Pirscher, B., Foelsche, U., Borsche, M., and Kirchengast, G.: Sampling of the diurnal tide of temperature using Formosat3/COSMIC data, in: New Horizons in Occultation Research, edited by: Steiner, A. K., Pirscher, B., Foelsche, U., and Kirchengast, G., Springer-Verlag Berlin Heidelberg, 131-140, doi:10.1007/978-3-642-00321-9_11, 2009.

Pirscher, B., Foelsche, U., Borsche, M., Kirchengast, G., and Kuo, Y.-H.: Analysis of migrating diurnal tides detected in FORMOSAT-3/COSMIC temperature data, J. Geophys. Res., 115, D14108, doi:10.1029/2009JD013008, 2010.

Randall, D. A., Harshvardhan, and Dazlich, D. A.: Diurnal variability of the hydrologic cycle in a general circulation model, J. Atmos. Sci., 48, 40-62, 1991.

Rocken, C., Anthes, R., Exner, M., et al.: Analysis and validation of GPS/MET data in the neutral atmosphere, J. Geophys. Res., 102, 29849-29866, 1997.

Schreiner, W., Rocken, C., Sokolovskiy, S., Syndergaard, S., and Hunt, D.: Estimates of the precision of GPS radio occultations from the COSMIC/FORMOSAT-3 mission, Geophys. Res. Lett., 34, L04808, doi:10.1029/2006GL027557, 2007.

Schrøder, T., Leroy, S., Stendel, M., and Kaas, E.: Validating the microwave sounding unit stratospheric record using GPS occultation, Geophys. Res. Lett., 30(14), 1734, doi:10.1029/2003GL017588, 2003.

She, C. Y., Chen, S., Williams, B. P., Hu, Z., Krueger, D. A., and Hagan, M. E.: Tides in the mesopause region over Fort Collins, Colorado $\left(41^{\circ} \mathrm{N}, 105^{\circ} \mathrm{W}\right)$ based on lidar temperature observations covering full diurnal cycles, J. Geophys. Res., 107(D18), 4350, doi:10.1029/2001JD001189, 2002.

Slingo, A., Wilderspin, R. C., and Brentnall, S. J.: Simulations of the diurnal cycle of outgoing longwave radiation with an atmospheric GCM, Mon. Weather Rev., 115, 1451-1457, 1987.

Smith, E. K. and Weintraub, S.: The constants in the equation for atmospheric refractive index at radio frequencies. Proc. IRE, 41, 1035-1037, 1953.

Soden, B. J., Tjemkes, S., Schmetz, J., et al.: An intercomparison of radiation codes for retrieving upper tropospheric water vapor in the $6.3 \mathrm{~mm}$ band, B. Am. Meteorol. Soc., 81, 797-808, 2000.

Sokolovskiy, S. V.: Effect of superrefraction on inversions of radio occultation signals in the lower troposphere. Radio Sci., 38, 1058, doi:10.1029/2002RS002728, 2003.

Sokolovskiy, S. V., Kuo, Y.-H., Rocken, C., Schreiner, W. S., Hunt, D., and Anthes, R. A.: Monitoring the atmospheric boundary layer by GPS radio occultation signals recorded in the open-loop mode, Geophys. Res. Lett., 33, L12813, doi:10.1029/2006GL025955, 2006.

States, R. J. and Gardner, C. S.: Temperature structure of the mesopause region $(80-105 \mathrm{~km})$ at $40^{\circ} \mathrm{N}$ latitude, 2, Diurnal variations, J. Atmos. Sci., 57, 78-92, 2000. 
Syndergaard, S.: On the ionosphere calibration in GPS radio occultation measurements, Radio Sci., 35, 865-883, 2000.

Tian, B., Soden, B. J., and Wu X.: Diurnal cycle of convection, clouds, and water vapor in the tropical upper troposphere: Satellites versus a general circulation model, J. Geophys. Res., 109, D10101, doi:10.1029/2003JD004117, 2004.

Tian, B., Held, I. M., Lau, N.-C., and Soden, B. J.: Diurnal cycle of summertime deep convection over North America: A satellite perspective, J. Geophys. Res., 110, D08108, doi:10.1029/2004JD005275, 2005.

Tsuda, T., Kato, S., Manson, A. H., and Meek, C. E.: Characteristics of semi-diurnal tides observed by the Kyoto meteor radar and Saskatoon medium-frequency radar, J. Geophys. Res., 93, 7027-7036, 1988.

Tsuda, T., Murayama, Y., Wiryosumarto, H., Harijono, S. W. B., and Kato, S.: Radiosonde observations of equatorial atmosphere dynamics over Indonesia 1. Equatorial waves and diurnal tides, J. Geophys. Res., 99(D5), 10491-10505, 1994.

Vorobev, V. V. and Krasil'nikova, T. G.: Estimation of the accuracy of the atmospheric refractive index recovery from Doppler shift measurements at frequencies used in the NAVSTAR system, Physics of the Atmosphere and Ocean (English Translation), 29(5), 602-609, 1994.

Wickert, J., Beyerle, G., Hajj, G. A., Schwieger, V., and Reigber, C.: GPS radio occultation with CHAMP: Atmospheric profiling utilizing the space-based single difference technique, Geophys. Res. Lett., 29(8), 1187, doi:10.1029/2001GL013982, 2002

Williams, B. P., She, C. Y., and Roble, R. G.: Seasonal climatology of the nighttime tidal perturbation of temperature in the midlatitude mesopause region, Geophys. Res. Lett., 25, 3301-3304, 1998.
Wu, D., L., Hays, P. B., and Skinner, W. R.: A least squares method for spectral analysis of space-time series, J. Atmo. Sci., 52(20), 3501-3511, 1995.

Wu, D. L., McLandress, C., Read, W. G., Waters, J. W., and Froidevaux, L.: Equatorial diurnal variations observed in UARS Microwave Limb Sounder temperature during 1991-1994 and simulated by the Canadian Middle Atmosphere Model, J. Geophys. Res., 103(D8), 8909-8917, 1998.

Xie, F., Syndergaard, S., Kursinski, E. R., and Herman, B. M.: An Approach for Retrieving Marine Boundary Layer Refractivity from GPS Occultation Data in the Presence of Super-refraction, J. Atmos. Ocean. Tech., 23, 1629-1644, 2006.

Xie, F., Haase, J. S., and Syndergaard, S.: Profiling the Atmosphere Using the Airborne GPS Radio Occultation Technique: A Sensitivity Study, IEEE T. Geosci. Remote, 46(11), 3424-3435, doi:10.1109/TGRS.2008.2004713, 2008.

Xie, F., Wu, D. L., Ao, C. O., Kursinski, E. R., Mannucci, A. J., and Syndergaard, S.: Super-refraction effects on GPS radio occultation refractivity in marine boundary layers, Geophys. Res. Lett., 37, L11805, doi:10.1029/2010GL043299, 2010.

Yang, G.-Y. and Slingo, J. M.: The diurnal cycle in the tropics, Mon. Weather Rev., 129, 784-801, 2001.

Zeng, Z., Randel, W., Sokolovskiy, S., Deser, C., Kuo, Y.-H., Hagan, M., Du, J., and Ward, W.: Detection of migrating diurnal tide in the tropical upper troposphere and lower stratosphere using the Challenging Minisatellite Payload radio occultation data, J. Geophys. Res., 113, D03102, doi:10.1029/2007JD008725, 2008. 